\title{
Acquiring geographic knowledge in international politics*
}

Luís Miguel da Vinha ${ }^{1}$

\section{Abstract}

Recent years have witnessed the emergence of a number of works relating geographic mental maps to international politics. Notwithstanding the various efforts to clarify and explain the conceptual framework underlying the geographic mental map research agenda, much theoretical bewilderment still persists. The concept of the geographic mental map has diverged considerably in definition and numerous methodological approaches have been undertaken. Consequently, no scholarly consensus has yet been reached. "Mental map" is still used as a catch-all term with only very vague notions as to its conceptual underpinnings. Several fundamental issues still need to be addressed. First and foremost, geographic mental maps are in need of a serious effort of conceptualization in order to be properly applied to the study of international politics. In particular, the question of how foreign policy decision-maker's geographic mental maps are formed has to date eluded a satisfactory response. With this in mind, this article shall consider some of the many ways individuals can acquire geographic knowledge from their political environment. For this purpose we draw from the vast theoretical and empirical literature that has emerged primarily from the fields of environmental psychology and behavioral geography. Despite the inherent limitations of adapting this knowledge to the field of foreign policy analysis, this literature is highly suggestive given that it serves as an important source of insight and hypotheses for those concerned with the understanding of foreign policy-maker's geographic constructs.

Key-Words: Cognition. Geographic knowledge. Geographic mental maps. International politics. Perception.

* Recebido em 30.09.2010.

Aprovado em 29.11.10.

1 B.A. and M.A. in Geography from the College of Humanities of the University of Coimbra. Doctoral Candidate in International Relations at the College of Economics of the University of Coimbra. Teaching Assistant at the Department of International Relations, College of Economics of the University of Coimbra - luisdavinha@gmail.com 


\section{Locating geographic mental maps in the field of international relations}

It has become a cliché in contemporary social sciences, particularly in International Relations (IR), to subscribe uncritically to the role played by cognitively constructed geographies, commonly referred to as geographic mental maps, in foreign policy decision-making. Even while recognizing that geographic mental maps are prone to numerous distortions, few authors would contest that "the decisions that lead to political action, however, are taken in the more amorphous, nuanced world of the mental map" (HENRIKSON, 1980a, p. 497). Political decision-makers need to make decisions based on information and events that are generally outside their national or even regional contexts. Therefore, mental maps are "systems of orientation" which are used for guidance in foreign policy-making (HENRIKSON, 2002).

To make sense of the diversity and complexity of the political world, decision-makers rely on simplified representations or mental models (GOLLEDGE; STIMSON, 1997; HOLSTI, 1976; 2006a; 2006b; RENSHON, 2006). No one individual can encompass the complexity of the world in its entirety. Even large bureaucratic institutions cannot process all the available information and produce an infallible portrait of the world (ALLISON; ZELIKOW, 1999; HENRIKSON, 1980a; KIESLER; SPROULL, 1982). Scientific studies have established that individuals and groups have cognitive spatial constructs which they use to simplify reality and aid political decision-making (GOLLEDGE, 2002; HENRIKSON, 1980a; O'LOUGHLIN; GRANT, 1990; MARK et al., 1999). Consequently, "the beliefs that compromise these maps provide the individual with a more or less coherent way of organizing and making sense out of what would otherwise be a confusing array of signals picked up from the environment by his senses" (HOLSTI, 2006b, p. 34).

More precisely, decision-makers act with regard to their perceived geographic context, meaning "what matters in the explanation of decisions and policies is how the actor imagined his environment to be, not how it actually was" (SPROUT; SPROUT, 1960, p. 147). Accordingly, different actors can respond differently to the same event in the international environment. As a result, mental maps are essential to policy-making in the sense that they are a "critical component of general spa- 
tial problem-solving activity" (GOLLEDG; STIMSON, 1997, p. 239). By informing decision-makers about particular geographic settings, mental maps contribute to the process of spatial choice and decision-making inherent in foreign policy.

Accordingly, the study of geographic mental maps has to be placed in the context of the cognitive research agenda in International Relations. The last two and a half decades have seen a substantial growth in cognitive research in IR (TETLOCK; MCGUIRE JR., 1999). The end of the Cold War left traditional IR theories wanting. Therefore, Valerie Hudson and Christopher Vore (1995) affirm that mainstream theories of IR were unable to predict the demise of the bi-polar confrontation and to explain the new complex international environment. In their critique of the time-honored theories that dominated IR, Hudson and Vore (1995) insist that there is a lack of comprehension of human political choice. Specifically, the established theories failed to recognize that "with every system transformation ... human will and imagination are major influences in shaping world affairs" (HUDSON; VORE, 1995, p. 210).

The alternative to the rational perspective came from what has become known as the cognitive revolution. This approach has guided a vast array of research in IR that departed from the traditional theories, particularly by viewing human rationality as bounded. Therefore, the cognitive approach is predisposed to examine the individuals involved in decision-making process and the complex environment in which they work. The advantages of using a cognitive approach are elegantly summarized by Jerel Rosati:

One feature all cognitive approaches share is that they provide an excellent perspective for determining the actual contents of the beliefs and images held by individual policymakers. A myriad of cognitive approaches can be drawn upon. For instance, the operational code emphasizes policymaker's broad beliefs about politics; the image of the "other" focuses on the policymaker's perceptions and beliefs concerning a particular actor in world politics; cognitive mapping tends to examine a policymaker's foreign policy belief toward very specifics issues. Whether a broad or narrow perspective is taken, a cognitive approach allows one to examine any aspect of a policymaker's foreign policy belief to contribute to a better understanding of foreign policy." (ROSATI, 2005, p. 60) 
Accordingly, the cognitive research agenda has focused on two types of strategies in its effort to simplify the understanding of how the different cognitive dimensions involved foreign policymaking function (TETLOCK; MCGUIRE JR., 1999). The first strategy corresponds to representational research, which relies on cognitive or knowledge structures that provide the framework for assimilating new informational inputs and choosing between the diverse policy options. Above all, these studies look to explain what policymakers think. This entails understanding their assumptions about themselves, other states, inter-state relationships, the goals and/or values underlying foreign policy, and the types of policies most helpful to achieving those goals or values. Some of the concepts most readily applied to describe these cognitive structures are "operational codes", "cognitive maps", "images", "schemas", "stereotypes", "scripts", "frames", and "prototypes".

The second strategy identified embodies process research, with its main focus on identifying the abstract laws of cognitive functioning that clarify how policymakers think about issues. The bulk of this research looks to comprehend the rules or procedures that are subjacent to the policymaking decision process. Some of the most significant lines of research in the process strategy are on the fundamental attribution error, extracting lessons from history, avoidance of value trade-offs, the policy-freezing effects of commitment, and crisis decision-making. Accordingly, in all these cases "the cognitive miser image of the decision maker serves as leitmotif: policymakers often seem unwilling or unable to perform the demanding information-processing tasks required by normative models of judgment and choice” (TETLOCK; MCGUIRE JR., 1999, p. 511).

Notwithstanding the recent proliferation of an assortment of cognitive approaches in foreign policy analysis, the geographic dimensions in cognition remain clearly lacking. Both the fields of Human Geography and IR have witnessed a move away from the dominant deterministic structural theories, towards a more cognitively oriented approach. Both have looked to understand how these cognitive constructions affect individuals' behavior and decision-making, developing, as a result, an assortment of models and methods of analysis and explanation. However, these common trajectories only intersected effectively with the work of Alan K. Henrikson. It was Henrikson's The Geographical "Mental Maps" of American Fo- 
reign Policy Makers, published in 1980, that first applied the "geographic mental

map" as a conceptual instrument for foreign policy analysis ${ }^{2}$. Acknowledging that traditional political science has long been ill-equipped to deal with the geographic perceptions underlying foreign policy decisions, Henrikson contends that the mental map permits a better understanding of how individuals come to understand their spatial relationship. More importantly, the use of mental maps "enables us immediately to recognize the vague and shifting character of the environments within which statesmen act. (HENRIKSON, 1980a, p. 505).

With the intention of providing a functional framework for analytical purposes, Henrikson expanded the existing conceptual knowledge on geographic mental maps. Accordingly, he begins by identifying the formational factors subjacent to mental maps - i.e., the maps cognitive base and a person's world-view (or Weltanschauung) - and proceeds to describe the appropriate methods for analyzing an individual's mental maps - the geographic mind and the geographic field. Examining the geographic mind, or "ideology" of the individual, can best be accomplished by making use of the methods of intellectual history and content analysis.

Nevertheless, Henrikson insists that it does not suffice to examine the ideological content of a decision-maker; "one must also have a reliable, nearly intuitive sense of the geographic milieu through which one moves" (HENRIKSON, 1980a, p. 505). This implies plotting the space in which an individual moves in carrying out his various occupational and social roles - i.e., the geographic field. By describing the actual life patterns of individuals (for example, his official travels), specifically by plotting the activity on cartographic charts, it is possible to record the geographic behavior of decision-makers and policy-makers. In brief, the two concepts can be hypothesized as typifying foreign policy planning (geographic mind) and the conduct of diplomacy (geographic field) (HENRIKSON, 1980a).

2 Henrikson (1975, p. 1980b) had previously analysed how geographic perceptions had influenced US foreign policy, especially through the analysis of different cartographical constructions. 
At the core of foreign policy-maker's geographic mind are what Henrikson (1980a, p. 512) designates as "image-plans", combining the visual and logical (or abstract) elements that inform their "grand strategies" and "grand designs". For its part, the geographic field comprehends an activity-generated space or "behavior-space", which results from personal experience (HENRIKSON, 1980a, p. 517). To fully understand how geographic mental maps influence foreign policy-maker's behavior, Henrikson argues these two factors must be considered together, for large-scale image plans may help keeping the environmental complexity in a comprehensible perspective, but "they must be accompanied by keen familiarity with smaller behavior-spaces at ground level" (HENRIKSON, 1980a, p. 525).

Henrikson's work encouraged some further research on geographic mental maps applied to international politics. However, theoretical development and empirical cases lagged. A decade after Henrikson published his essay on mental maps, John O'Loughlin and Richard Grant (1990, p. 507) conceded that "to date researchers have not attempted to relate cognitive maps and political images". Henrikson (2002) took up his previous argument once more in Distance and Foreign Policy: A Political Geography Approach. He insists, yet again, that "Geographical ideas, images, and associated reasoning processes, which may not be completely conscious or fully articulated in speech, do exist in the minds of foreign policy makers" (HENRIKSON, 2002, p. 440-441). In particular, cognitively constructed distance is important in foreign policy-making. Distancing himself from his critics, Henrikson defends that these distance schemes correspond to how foreign policy-makers actually think when they strategize and plan:

This is "practical geopolitics", characteristic of the reasoning that occurs in foreign policy bureaucracies and political institutions, as distinct from what Gearóid Ó Tuathail and Simon Dalby, in their taxonomy term "popular geopolitics", characteristic of the mass media, and "formal geopolitics", characteristic of the academe. (HENRIKSON, 2002, p. 439-440)

In spite of reinforcing the importance of the influence of geographic cognitions on foreign policy, Henrikson's work has had few followers. While some studies dedicated to geographic cognition have been published in recent years (see BILGIN, 2004; GLASSMAN, 2005; LATHAM, 2001; LE RIDER, 2008; SCHE- 
FFLER, 2003; WALKER, 2000), most have tended to focus on regional perspectives. Other works, while more global in scope (see BIALASIEWICZ et al., 2007; LEWIS; WIGEN, 1997; SLOAN, 1988), have not focused directly on the way that geographic mental maps inform the decision-making and policy-making processes $^{3}$. Rather they have tended to concentrate on the way geographic constructions justify foreign policy decisions.

In fact, some of the epistemological propositions stressed by the earlier work on mental maps have come under criticism from critical geopolitics. Klaus Dodds (1994) has questioned the geographic practice of representing the political world, specifically calling on critical and post-structuralist theories contributions to point out that “'geography' (or 'international relations') as a technology or an academic discipline is not simply about 'geographing' or 'earth-writing', i.e., a practice whereby geographers simply record the already legible surfaces of the earth" (DODDS, 1994, p. 187). According to Dodds, discourses of geographic representations are frequently central to the legitimization of foreign policy which fix the boundaries between "Us" and the "Others".

Critical geopolitics is thus centered on exploring how foreign policy professionals represent political space according to their position in the world. This differs from previous research according to Dodds (1994, p. 197) who criticizes Henrikson's work on mental maps for having "little recognition that the observer might be implicated within these observations or that it might be reasonably problematic in assuming one could (re)present the activities of others". Consequently, scholars committed to critical geopolitics have developed much of the work on geographic representations in foreign policy. Relying on discourse analysis and similar methods, the central assertion of critical geopolitics is "that geography is a social and historical discourse which is always bound up with questions of politics

\footnotetext{
3 In fact, many of these studies do not apply the "mental map" as their analytical concept. Many different terms are used to characterize the cognitively constructed geographies informing foreign policy - e.g., "cognitive geopolitics" (CRIEKEMANS, 2009), "geopolitical codes" (DIJKINK, 1998), "geopolitical images" (O'LOUGHLIN; GRANT, 1990), "geopolitical imaginary" (Latham, 2001), "geopolitical imagination" (AGNEW, 2003) "imaginative geographies" (BIALASIEWICZ et al., 2007), and "metageographies" (LEWIS; WIGEN, 1997).
} 
and ideology" (Ó TUATHAIL; AGNEW, 1998, p. 79). More specifically, critical research has centered on the way spatial discourse has legitimized the practice of hegemony in the international system (Ó TUATHAIL, 1992).

More recently, some researchers have (re)turned to analyzing the mental maps of particular decision-makers, revealing their world-views. Returning to

a familiar theme ${ }^{4}$, Henrikson (2008) has examined how Franklin D. Roosevelt's (FDR) mental map or "geographic-cartographic frame" conditioned US policy, namely by molding popular conceptions of world geography. In a similar vein, Steven Casey and Jonathan Wright (2008) recently edited a collection of essays on various world leaders' mental maps during the interwar period. Applying the concept of mental maps as tantamount to political worldviews, the authors explore the geographic conceptions that constrained the policy-making of numerous national leaders. While constituting the single most extensive work on different foreign policy-maker's mental maps, the study does not present any theoretical framework for applying the mental map approach. More recently, in September 2009, at Oxford University, the same academics convened a Conference on Mental Maps in the Early Cold War Era. Some theoretical questions were discussed, namely how mental maps are formed and how they influence foreign policy-making. However, many questions still remain unanswered and await developments in the research of the topic.

In summary, there have appeared a number of works relating geographic mental maps to foreign policy in the last couple of decades. However, despite the various efforts to clarify and explain the conceptual framework underlying the geographic mental map research agenda, there still persists a good deal of theoretical bewilderment. The concept of geographic mental map has diverged considerably in its definition and numerous methodological approaches have been undertaken. Consequently, no scholarly compromise has yet been established.

${ }^{4}$ Henrikson (1975) had previously studied how US geographic conceptions had been transformed by a change in the cartographic representations during the Second World War period (namely by adopting an "Air-Age Globalism" perspective). 
"Mental map" is still used as a catch-all term with only very vague notions of its conceptual underpinnings.

In particular, several essential issues still need to be addressed. First and foremost, geographic mental maps are in need of a serious conceptualizing effort in order to be applied to the study of international politics. Recent decades have in fact witnessed a plethora of approaches in the research agenda of geographic

cognition that has expanded to include a wide assortment of issues ${ }^{5}$ (GOLLEDGE; STIMSON, 1997). Notwithstanding the continued significance and development of research on geographic cognition, most studies focus on scales that range from the micro-space (space of the body) to the neighborhood or city scale. Cognitive research of large-scale spaces, such as the global-scale, is infrequent. One of the principal reasons for the lack of research of large-scale environments is due to their transperceptual dimension. This implies that large-scale spaces "are generally too large to be perceived all at once" and can only be experienced "by the integration of perceptual experiences over space and time through memory and reasoning, or through the use of small-scale models such as maps" (MARK et al., 1999, p. 748; see also BATTERSBY; MONTELLO, 2009).

Some studies have devoted themselves to these larger geographic scales ${ }^{6}$. Most of these studies however tend to concentrate on very specific theoretical and methodological issues, applying very empirically oriented approaches. More precisely, the majority of the contemporary studies of large-scale geographic cognition are interested in the acquisition, representation and schematization, and commu-

\footnotetext{
5 Some of the issues that have received more attention are 1) studies of cognitive mapping and spatial behavior; 2) attitudes, utility, choice, preference, search, and learning; 3) consumer behavior; 4) location decision-making; 5) way-finding, mode choice, and travel behavior; 6) mobility and migration behavior; 7) societal, materialist, or feminist interpretations of urban structure; 8) social reality of housing markets; 9) environmental ethics; 10) planning and policy-making; 11) social problems of the homeless and other disadvantaged groups.

6 For a detailed account of the scientific work done on large-scale geographic space (globalscale) see Allen (1985), Battersby and Montello (2009), Golledge and Stimson (1997), Mark et al. (1999), and Montello (1998).
} 
nication of spatial information (MARK et al, 1999). This information is of particular concern to researchers working on problems of navigation and orientation (TVERSKY, 2003). Studies on distortion of acquired geographic information have been equally significant in recent years (BATTERSBY; MONTELLO, 2009). For the most part, however, studies of large-scale environments have avoided analyzing the implications of mental maps in human decision-making and behavior in international politics. In particular, the question of how foreign policy decision-maker's geographic mental maps are formed has eluded a satisfactory response.

Taking the above into consideration, this article shall consider some of the many ways individuals can acquire geographic knowledge from their political environment. For this purpose we shall draw, in a necessarily selective way, from the vast theoretical and empirical literature bearing upon this problem that has emerged mainly from the fields of environmental psychology and behavioral geography. Despite the inherent limitations of adapting this knowledge to the field of foreign policy analysis, this literature is highly suggestive given that it serves as an important source of insight and hypotheses for those concerned with the understanding of foreign policy-maker's geographic constructs. Used with caution, it can sensitize and aid both those who study foreign policy-making and those who participate in it

\section{Acquiring geographic knowledge}

There are many different ways of acquiring geographic information about the world. Depending, in large part, on the size of the area we are dealing with, various methods are available. We can acquire geographic knowledge through direct or indirect experience (BATTERSBY; MONTELLO, 2009; KITCHIN; BLADES, 2002; MARK et al., 1999). Accordingly, using different methods leads to the development of distinct mental maps, with varying levels of detail and accuracy (BATTERSBY; MONTELLO, 2009; LLOYD, 1989).

Already in the $18^{\text {th }}$ century, Immanuel Kant had acknowledged space as a category of thought and identified three mechanisms through which humans acquire knowledge (PEUQUET, 2002; p. 35): 
1. Sense - the perception and recognition of specific sensory stimuli;

2. Apperception - the recognition and categorization of combinations of remembered and current sensory inputs as a unified and sensible experience;

3. Imagination - the association and synthesis of ideas without direct sensory output.

In this sense, Kant affirmed that the acquisition of knowledge involved an inherent judgment. Breaking with the traditional affiliation of knowledge to external authority, Kant's thinking echoed the growing confidence in individual human reason of the early Modern Era in which " $[\mathrm{m}]$ en began to acquire a degree of confidence in their ability to discover truth by searching for it, and an assurance that opinions were valid if well attested by reason" (DIXON ${ }^{7}, 1900$ : iii). Accordingly, for Kant, since there is no way to comprehend the nature of "reality" except through man, it is impossible to entirely separate the process of knowing from the ensuing knowledge. Therefore, a complete understanding of truth in either sense or reason is unfeasible. As an alternative, Kant argued that "instead of naively assuming that knowledge can ever represent exactly what is real, we are led to the conclusion that what we take to be real is a product of knowing (a construction of thought)" (HART; MOORE, 1974, p. 252). By acquiring knowledge, individuals are in fact judging what is true and what is false, what is useful and what is not (PEUQUET, 2002).

However, it was Piaget who developed the most inclusive and influential theory of spatiotemporal cognition (HART; MOORE, 1974; GOLLEDGE, 1987). In his theory, children advance successively through various stages of development "from an initial, practical, sensory-motor stage, in which knowing is tied to the child's own actions, to a mature stage, which includes what he referred to as logicomathematical thinking" (PEUQUET, 2002, p. 39). Therefore, as an individual evolves his understanding of the world is less dependent on direct sensory stimuli from the external environment and more on abstract and reflective thought. This process also implies an alteration in the individual's viewpoint, in which a perspective view replaces an egocentric view, centered on one's own self.

7 From Brandt Dixon's Introduction to Kant (1900). 
Although Piaget's theories of cognitive development have been subject to numerous criticisms, his work, along with Werner's, offer "a substantial body of evidence that although environmental and cultural influences may vary considerably, both the process of knowledge acquisition and an initial biological motivation, upon which all other cognitive constructs are built, are universal" (PEUQUET, 2002, p. 40). More precisely, Piaget distinguished between figurative and operative knowledge. Whereas the former consists of familiar elements in the environment, the latter consists of generalized knowledge that allows us to comprehend spatial interrelationships. These dissimilar types of knowledge are acquired gradually as a child develops, in accordance with several different stages of development: sensory-motor stage, preoperational stage, concrete operations stage, and formal or hypothetic-deductive operations stage (PIAGET, 1997).

The overall value of Piagetian theory is, according to Peuquet (2002, p. 46), "that the acquisition of knowledge is, generally speaking, a progressive, complex, and self-adapting process that relies on interaction with, and reasoning about, the outside world". However, geographic-scale space cannot be perceived directly, complicating the theoretical rationale alluded to above. While various researchers promoted theoretical frameworks for dealing with such large scale environments (see GOLLEDGE; STIMSON, 1997; KITCHIN; BLADES, 2002; LYNCH, 1960; MONTELLO, 1998, TVERSKY, 1993), namely through route, landmark, and survey knowledge, the limitations of direct observation have been acknowledged. In particular, geographic knowledge sometimes involves the use of deduction, based on previously existing knowledge. Accordingly, in addition to sensory-motor experience, other means are available to understand our broader spatial contexts:

The acquisition and subsequent use of language represents a specific advantage in learning about, and dealing with, the real world. Knowledge about peoples, places, and things also includes knowledge acquired by means other than direct sensory experience and introspection. Knowledge is often acquired from verbal descriptions, photographs, maps, and even watching television. Certainly, indirect means are the only way to learn about things on a geographic or temporal scale too large to be experienced directly under usual circumstances... (PEUQUET, 2002, p. 50) 
In this sense, direct experience is only the initial condition for knowledge attainment. Other ways must also be considered, especially in the circumstances of international politics. In the subsequent sections we will explore these different acquisition processes, highlighting their significance to the decision-maker's understanding of the political world.

\subsection{Acquiring Geographic Knowledge Through Direct Experience}

The most commonly studied and effortless form of acquiring geographic knowledge is through direct physical experience or, more fittingly, through our sensory modalities (DOWNS; STEA, 2005; GOLLEDGE, 1987). The content of this "primary" knowledge "is navigation-based, with the collection and processing of spatial information explicitly linked to an individual's interaction with an environment through spatial activity" (KITCHIN; BLADES, 2002, p. 35). More precisely, it is through the combination of visual, tactile, olfactory, and kinesthetic sense modalities that we create an integrated representation of our spatial environment (DOWNS; STEA, 2005). However, for analytical purposes, cognitive psychology has applied single sense analysis in order to understand how the individual stimuli obtain information from their surroundings. According to Peuquet (PEUQUET, 2002), vision and haptics - i.e., tactile senses - are the most regularly studied modalities and deemed the most direct perceptual sources of our environment. We shall focus the bulk of our attention on these two senses in order to grasp the underlying dynamics involved in primary learning.

Vision has long been considered the most fundamental sense in spatial understanding, namely functioning as an information-processing task. In the cognitive literature vision is typically divided into low-level and high-level processing. While low-level vision is identified as the preliminary processing of the "raw", untreated retinal images ${ }^{8}$, high-level vision applies this initial process and utilizes previously accumulated knowledge to identify individual objects, to relate added

8 The "raw" images are understood to consist of the vast assortment of varying color hues and concentrations of light intensities that are altered as the objects and the viewer move through within or through the visual field (PEUQUET, 2002). 
properties with those objects, to bestow meaning to the entire view, and to direct ensuing observations (PEUQUET, 2002) Low-level vision and at least the initial stages of high-level vision are generally associated with pattern recognition, meaning that the "raw" images are organized and objects are identified through the comparison of the sensory stimuli to a particular pattern already stored in memory.

According to Peuquet (2002, p. 95) there are four pattern recognition approaches:

1.template matching - begins with a specific pattern previously identified in the scene which is then compared to a set of templates formerly stocked in memory (a typical example of the template matching procedure is illustrated in Figure 1, in which the uppercase letter $R$ is printed with several variations in form, but is quickly recognized and distinguished from other letters). However, the template model are only useful for standardized shapes which are in their complete form;

2.prototypes-moreflexible models that match moreidealized patterns, such as in text-scanning software. The limits of model are in the restricted variation of a given prototype. (An illustration of the confines of this model can be once again obtained through Figure 1. While encompassing an assortment of different script style prototypes, a standard scanner software would have difficulty in recognizing the second - i.e., Old English Text MT - and fourth letters - i.e., Blackadder ITC - without the appropriate extensions);

3.distinctive features - supported by research in the field of biology this model argues that individuals distinguish amongst numerous stimuli on account of a small number of characteristics. Accordingly, the visual system contains physical components that act as "special feature detectors" which allow the individual to visually distinguish objects; 4.structural descriptions - this is a more intricate model based on distinctive features that stresses the relations among features as an important factor in the identification and distinction of the features themselves. The major criticism to this model (in the same way as the distinctive features model) is that it is highly unreasonable to assume that individuals can cognitively imagine the extensive variety of the low-level elements for regular, everyday scenes. 


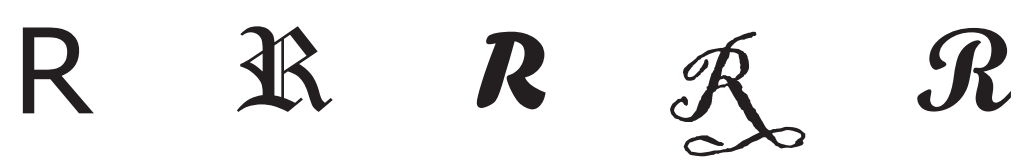

FIGURE 1 - ASSORTMENT OF LETTER FORMS THAT ARE EASILY IDENTIFIED AS THE LETTER $R$

Application and empirical testing of these different theories have yet to validate their accuracy and legitimacy. In fact, Peuquet (2002, p. 97) questions the complexity of these diverse models, arguing that the process of visually acquiring information about our environment is "immediate, effortless, and veridical". To facilitate our understanding of how specific objects are easily picked-out and identified consistently from the complexity of our environment Peuquet (2002) evokes James J. Gibson's ecological theories of visual perception and their focus on the principles of similarity, proximity, direction, and good gestalt (i.e., good form) in the organization of pictures. Gibbon's stated that these principles form the invariant properties of the natural world, unwavering through movement or change in the observer's view. Ultimately, these invariants "can be thought of as higher-order properties of patterns of stimulation that remain constant during changes associated with the observer, the environment, or both" (GORDON, 2004, p. 153).

Gibson's ecological theory paved the way for Marr's primal sketch which unified for the first time many of the existing theories on vision (PEUQUET, 2002). Marr argued that elements are initially obtained from the raw image and subsequently stored as "tokens" which are assembled and given a specific value for its attributes, e.g., size or orientation. On the whole, Marr presented a model that developed from deriving tokens from an image, such as lines, curves, and areas, to assembling them into surfaces and ultimately into volumetric models. While Marr's theory has been recognized as useful for understanding the visioning process, Peuquet has identified an important fault:

It assumes a one-way process in which we start with the image and successively assemble features, and then associate them with stored concepts in a bottom-up process. The opposite, Gestalt approach would be first to match large units and then fill-in smaller details in a top-down manner. More realistically, this process works both ways. Knowledge about what is expected in the scene (from stored concepts) is also used to speed interpretation of future images. (PEUQUET, 2002, p. 101) 
Although the other senses do not absorb researcher's attention to the extent that vision does, their perceptual processes are comparable in nearly every feature:

There is a significant overlap between the characteristics of the experiential world and the things within it can be picked up by various senses. Vision conveys information about size, distance, shape, and texture, as well as uniquely visual characteristics, such as color and brightness. Hearing conveys information about size and distance, as well as uniquely auditory characteristics. All rely on the recognition of pattern. (PEUQUET, 2002, p. 104)

For instance, auditory perception allows individuals to separate the sounds received from their environment and decode the separated sounds into meaning-

ful information. Individuals can achieve an auditory scene analysis ${ }^{9}$ by dividing the overall process into simultaneous groupings and sequential groupings (PLACK, 2005). The process of simultaneous grouping assigns sounds that occur simultaneously to different sources, whereas the process of sequential grouping allocates sequences of sounds, such as musical melodies or sequences of words, to different sources. In keeping with the premises of early Twentieth-Century Gestalt psychologists, individuals organize their precepts according to certain principles or "rules of thumb" that help make sense of the complex mixture of sounds acquired

from the environment ${ }^{10}$. These principles, in reality, "ensure that our perception of 'natural' sounds is organized into the simplest pattern consistent with the sensory information and with our experience" (PLACK, 2005, p. 95).

\footnotetext{
9 Consists in the separation of the sounds coming from different sound sources.

${ }_{10}$ The most significant principles are 1) similarity - sounds that are alike in some way are expected to come from the same sound source; 2) good continuation - sounds that flow naturally from one to the other (without any sudden discontinuities) are likely to come from the same sound source; 3 ) common fate - sounds that vary together (for example, are turned on and off at the same time) are likely to come from the same sound source; 4) disjoint allocation - no single sound can originate from two different sources at the same time; and 5) closure - a continuous sound obscured momentarily by a second sound is alleged to be continuous during the interruption except if there is evidence to the contrary (PLACK, 2005).
} 
However, the sense of touch, i.e., haptics, does reveal a number of distinctive characteristics. First of all, the haptic "organ" is not concentrated in some fixed location in the body. On the contrary, the nervous system that conveys haptic information is dispersed all over the body in the form of nerve endings. Especially significant from a geographic perspective is the fact that haptic sensation is spatially constrained to the immediate space of the body. Also, haptic sensation is restricted temporally. While visual and auditory sensations can be fashioned by a plethora of sights and sounds distantly located from the individual, touch works on a more personal and intimate scale. Consequently, since touch is spatially more inhibited, it "has an obvious disadvantage in providing direct experiential information about geographic-scale space" (PEUQUET, 2002, p. 105).

Certainly all the senses are important for acquiring information about our environment. No one sensory modality can contribute by itself to our total experience of the world around us. Rather, all the senses are continuously supplying us with the geographic information necessary to cope with our environmental complexity. Ultimately, the entire sensory process functions in a much more complete manner than the sum of each individual sensory component.

However, our primary understanding of the environment is not simply the result of observation and direct experience. Once acquired through the sensory modalities, the information must be associated and integrated into our existing knowledge structure in order to confirm similarities, identify and resolve discrepancies, and establish connections across domains. It is up to the human imagination to help assemble a unified world view and generate a more comprehensive understanding of the environment (PEUQUET, 2002). Therefore, mental imagery and metaphors are the two main mechanisms applied in order to generate an understanding of the environmental situation. In a very heuristic manner, Peuquet distinguishes between the two:

Imagery employs our perceptual capabilities, often with purely mental constructions, for quickly perceiving continuities, discontinuities, and pattern. The metaphor establishes linkages and correspondences between different knowledge domains. Imagery and metaphor, as well as facts and relationship, can be conveyed via language and graphic images. (PEUQUET, 2002, p. 117) 
Mental images are the result of remembered perceptions as well as abstract constructions absent from direct personal experience. What's more, mental images can represent abstract idealized category prototypes which do not result from any remembered experience. Rather, they can be the consequence of a combination and refinement of several memories (LLOYD, 1982; TUAN, 1975). This diverse arrangement of sources gives mental imagery the means to combine elements in different ways, mentally transforming them and allowing us to resolve various types of spatial problems.

Metaphors, for their part, serve as linguistic surrogates. In other words, in language they substitute on word for another, facilitating the association across diverse sensory or emotional perceptions. One example cited by Peuquet (2002, p. 123 ) involves synesthetic perception, where "sounds (e.g., music or voices) are perceived to have visual properties, such as shapes, textures, or colors". Another case is illustrated by Peuquet (2002, p. 123) regarding physiognomic perception in which "dark colors or dark-colored objects are perceived as gloomy, and bright colors are perceived as happy". In general, the importance of mental images and metaphors is their capacity to assist in the integration of new knowledge into our preexisting knowledge structures, facilitating active learning.

Concurrently, it seems reasonable to assume that most foreign policy decision-makers do not and cannot physically relate with all the different places with which they have to deal with politically. Certainly we can sympathize with Henrikson's (1980a) concepts of geographical field and behavior spaces, which focus on the decision-maker's lived space. If we can theoretically accept that "the activity that is most relevant to awareness of large-scale environments is, of course, physical movement" (HENRIKSON, 1980a, p. 510), we hold serious reservations to overemphasizing policy-makers direct material knowledge of distant places. We cannot acknowledge the importance Henrikson attributed to statesmen's behavior spaces - i.e., the activity generated spaces that foreign policy-makers directly experience through their international travels - because the geographic knowledge of most foreign policy decision-makers does not lend itself to such material and objective sources. 
Ultimately, the geographic space of most foreign policy decision-makers is too vast to be perceived directly. In fact, geographic-space is best understood as transperceptual, i.e., experienced only "by integration of perceptual experiences over space and time through memory and reasoning", or though the use of indirect sources of information (MARK et al., 1999, p. 748). Besides the deductive nature of most human geographic knowledge, it is widely accepted that there are other ways of acquiring geographic knowledge, especially of large-scale spaces:

Knowledge about people, places, and things also includes knowledge acquired by means other than direct sensory experience and introspection. Knowledge is often acquired from verbal descriptions photographs, maps, and even watching television. Certainly, such indirect means are the only way to learn about things on a geographic or temporal scale too large to be experienced directly under usual circumstances, such as the shapes of the continents (or the shape of the earth) and continental drift. (PEUQUET, 2002, p. 50)

In addition, theories of foreign policy decision-making have acknowledged that decision-makers obtain most of their information from indirect, secondary sources (ALLISON; ZELIKOW, 1999; BLOODGOOD, 2003; GEORGE, 1980; VERTZBERGER, 2002). Besides official organizational and bureaucratic sources, decision-makers rely increasingly on informal personal and technological networks for acquiring their information (BLOODGOOD, 2003). As a result, we must how try to comprehend how decision-makers acquire geographic knowledge from other sources. The exigency of this desideratum is stressed by Vertzberger (2002, p. 53) when pointing out that "decisionmakers are not, however, willing - or, even more important, able - to pay attention to all sources of information available to them and decide what is relevant". Consequently, understanding how decision-makers acquire information from indirect experience is often essential to understanding foreign policy choices.

\subsection{Acquiring Geographic Knowledge Through Indirect Experience}

We should begin by emphasizing our conviction that the geographic space of the majority of foreign policy decision-makers is the entire globe. As previously 
mentioned global-scale geographic space cannot be perceived directly, for practical limitations make experience via physical contact and locomotion impossible (FREUNDSCHUH; EGENHOFER, 1997; MARK et al., 1999). This does not mean, however, that we cannot understand large-scale geographic space or places where we have never been personally. There are a number of different ways of acquiring geographic information through indirect experience (DOWNS; STEA, 2005; FREUNDSCHUH; EGENHOFER, 1997; GOLLEDGE, 1987; GOLLEDGE; STIMSON, 1997; LLOYD, 1982; MARK et al., 1999; PEUQUET, 2002; TVERSKY, 2003). As Kitchin and Blades (2002, p. 44) suggest, indirect experience, or secondary learning, "is the only source of information about environments at scales that cannot be experienced directly, such as countries or continents".

Indirect knowledge acquisition also contrasts with direct acquisition for the reason that the former is greatly reliant on cognitive processes. Whereas direct experience is a matter of perception, i.e. reacting to the immediacy and physical stimulus, cognition need not be directly related to the proximate environment (GOLLEDGE; STIMSON, 1997). This distinction is essential to a clear understanding of how geographic mental maps work, especially in the context of foreign policy decision-making, and therefore it is worth furthering this concept. As a matter of fact, perception and cognition are many times employed in a bewildering variety of contexts, creating some uncertainty as to what phenomenon is actually being addressed. The field of international politics is particularly prone to this conceptual muddling. In the field of IR perception is applied as a broad, all-inclusive concept that comprises the totality of perceptions, memories, attitudes, preferences, and other associated psychological dynamics ${ }^{11}$.

What we are habitually dealing with in IR is actually of a cognitive nature. Cognition refers to the psychological processes by which individuals acquire,

\footnotetext{
${ }^{11}$ We will admit that the reason for this misuse is lexical. Although political psychology has consolidated its position in international politics, the language of psychology has naturally limited application in politics. Moreover, it certainly sounds more graceful to say "the decision-maker perceived" than "the decision-maker cognized". Consequently, we are certain that when researchers use the term perception describing phenomenon in international politics, they are in fact referring to the process of cognition.
} 
process, store, and act on information from their environment. These include perception, learning, memory and decision-making (COTTAM et al., 2004; SHETTLEWORTH, 2010). While both perception and cognition refer to the processes responsible for the organization and interpretation of information, cognition is a broader concept that includes perception as well as other more complex psychological factors, such as those identified by Moore and Golledge:

In its most general sense, then, cognition refers to the various means of awareness or knowing that intervene between external energy impingements in the present and in the past and the entire gamut of human behavioural responses present and future. Cognition thus subsumes the more specific concepts and substages of sensation, perception, imagery, retention and recall, reasoning and problem solving, and judgement and evaluation. As such, it includes the various processes by which the visual, linguistic, semantic, and behavioural information is selected, encoded, reduced and elaborated, stores, retrieved, decoded, and used. (MOORE; GOLLEDGE, 1976, p. 6)

Whereas both perception and cognition generate mental representations of the objective environment, geographic scale is an important factor contributing to the distinction between the two. Set on a more spatial perspective, David Stea advocates that cognition occurs when the spaces under consideration are either occluded or too extensive to be perceived or apprehended all at once. Therefore these extensive, large spaces "have to be committed to memory and cognitively organized to contain events and objects that are outside the immediate sensory field of a person" (GOLLEDGE; STIMSON, 2007, p. 191). Ultimately, the fundamental distinction resides in the fact that perception deals with how an individual experiences the world, while cognition pertains to how an individual understands the world (COHEN, 1985).

Accordingly, the two most important means of acquiring nonsensory knowledge about the world are graphic images and language (PEUQUET, 2002). Both can assume an assortment of different forms. Graphic images may be obtained through maps, photographs, illustrations, diagrams, paintings, drawings, etc. Language can take a written or spoken form and be natural (e.g., English) or formal (e.g., mathematical). These secondary sources of knowledge are particularly im- 
portant due to their cumulative properties. More exactly, images and language, in their multiple forms, can be used to collect, record, and transmit events and information to future generations, granting them a certain permanence:

Besides being able to convey knowledge about places and times we have never seen, both the written word and the image have permanence that can be used to record information and document past events. Both also serve as repositories of information that gradually evolve and accumulate through successive versions, and by different individuals. Thus, besides being essential for providing indirect experience and conveying knowledge, graphics and language serve as key methods of external knowledge representation that provide means of recording and accumulating the collective knowledge and beliefs of a culture, and have an existence separate from any single person. (PEUQUET, 2002, p. 140-141)

The implications of these cumulative properties for foreign policy are immense. Decision-making, especially in the realm of foreign policy, is highly dependent on information processing (GEORGE, 1980; MINTZ; DEROUEN Jr., 2010; VERTZBERGER, 2002; VOSS, 1998). The information gathered, analyzed, and presented to decision-makers surely incorporates this accumulation of past perspectives and experiences. Moreover, the routine logic underlying most policy informing organizations (e.g., standard operation procedures) does not regularly lend itself to revaluations of the existing information. Logically, cumulative beliefs and values are protracted throughout the regular foreign policy-making process.

In the subsequent sections, we will explore how graphic images and language contribute to our geographic knowledge.

\subsubsection{Graphic images and geographic knowledge}

According to Peuquet (2002) the graphic perception process is identical to the normal visual perception process, which entails firstly the identification of the individual elements and secondly identifying the interrelationship between these elements. The second stage consists of the spatial arrangement and the distinction 
of the visual characteristics of the individual elements and is critical in graphic perception since it is within this arrangement and variation that we can identify the message.

Graphic images are constructions of our environment used to communicate different information. They are simplified representations of the material world in which specific objects and events are depicted in some kind of schematic form. In order to illustrate the meaningful but complex relationships of the real world on a sheet of paper, a video screen, or some other kind of means of display, images must distort reality (MONMONIER, 1999). Naturally, some elements are highlighted while others are obscured. As Peuquet (2002, p. 142) elucidates "even the most "realistic" graphic images, such as photographs, are simplifications achieved through the selection of the scene, choice of color or black-and-white film, length of exposure, and other devices".

Equally significant, each individual adjoins his own distinctive perspective to an image in accordance with his personal knowledge, experience, and culture. Thus, besides the deformations instilled by the producers of the images, we must take into consideration the individual perceiver's particular interpretation as well. In this sense, graphic images can be considered "knowledge-weighted" by information existing in long-term memory. Therefore, images, such as maps, are not learned in a conceptual void, but rather "map representations are influenced by information already in memory" (KULHAVY; STOCK, 1996, p. 126).

Prior knowledge affects learning in a variety of ways (LLOYD, 2002). In effect, readers with similar previous experiences can be capable of structuring novel information in long-term memory more efficiently than non-experienced readers. The development of relations between new and previously held information can lead to multiple and redundant retrieval paths in the cognitive structure storing the information. Also, during the learning process, access to prior knowledge can diminish the effort of working memory and augment the capacity to process more information in a fixed amount of time. Preexisting knowledge can similarly direct attention more selectively, using more useful information while ignoring that of less value. In addition, prior knowledge regarding a particular topic can 
be activated to aid the retrieval of information from memory. More accurately, prior knowledge can assume the form of an organized knowledge structure, such as schema, which guides perception and assists in the storage and recovery of information. Moreover, existing knowledge reduces encoding time since fewer propositions regarding the new information need to be encoded if they already exist.

As previously mentioned, there are many types of graphic images that convey geographic knowledge. Nevertheless, maps are usually identified as one of the most significant, especially at large geographic scales (BATTERSBY; MONTELLO, 2009). Maps differ in their communicative capacity from language in a number of ways (NEWCOMBE; HUTTENLOCHER, 2006). To begin with, maps necessarily incorporate metric relations, which are discretionary with regards to language. In addition, maps must show all the illustrated relations simultaneously, which is not feasible using language alone. What's more, the particular importance of the map is that which is conveyed through its scale, providing a nearly instantaneous way of experiencing large geographic spatial realities indirectly. As Paul Claval (2006, p. 137) so vividly put it, the map "transforms the observer into a giant capable of capturing a region, a country or a planet with a single glance”.

For the purpose of our present account we regard the map to be a physical layout of symbols that represent a set of objects and places (LANDAU, 2002). Thus, maps are different from other images, such as photographs, in the sense that the spatial data has been previously organized and represented as spatial information for communicational purposes (LLOYD, 2002). Accordingly, the map's spatial information becomes spatial knowledge when the patterns in the information are learned by the individual reading the map.

In very much the same way as with common graphics, the mapping process entails a "complex system of signs and "rules of grammar" and an arrangement within which an overall portrayal is shaped through selection, transformation, and arrangement" (PEUQUET, 2002, p. 150). This implies that the context of the map, the meaning of the individual symbols and the basic "rules of grammar" must be previously known if the map's message is to be understood. While this might seem an unfeasible task, Raymond Kulhavy and William Stock (1996) avow that indi- 
viduals acquire a wide gamut of culturally specific skills for understanding maps since early childhood. More precisely, according to the authors (KULHAVY; STOCK, 1996, p. 124), "maps are unique stimuli in our society, hence our perception of "maplikeness" (based on our prior knowledge) triggers a variety of practiced cognitive maneuvers". As a result, the development of a set of map learning skills throughout our life allows us to comprehend the information contained in the maps without great difficulty. According to Robert Lloyd (2002) map reading is an endeavor involving simultaneously the integration and synthesis of knowledge, requiring bottom-up and top-down information:

The bottom-up information is contained in the lines, colours, shapes, words, etc. the cartographer has put on the map. The top-down information is prior knowledge previously acquired by the map reader. It might be general factual knowledge learned in another context, but applicable to map reading, e.g., the meaning of words or the common names for colours. It might be cognitive abilities to process information that was learned and practiced in other contexts, but applicable to map reading. Examples might be judging distances between objects, comparing sizes of objects, distinguishing colours, counting, reading, etc. (LLOYD, 2002, p. 90)

But it is precisely the simplification of map representations that gives it its influence and effectiveness. By portraying some features over others the map permits viewers to focus on particular elements. Indeed, "the value of a map depends on how well its generalized geometry and generalized content reflect a chosen aspect of reality" (MONMONIER, 1999, p. 25). We emphasize the "chosen" quality of maps information for it is never exaggerated to stress a maps biased nature. Notwithstanding the technical proficiency involved in cartographic production, maps are ultimately the result of a creative process (PEUQUET, 2002).

The power of maps on foreign policy has been extensively studied in recent years. Some of the better works have focused on how maps influence individual leaders as well as collective understandings (CASEY; WRIGHT, 2008; HENRIKSON, 1975; 1980b; SCHULTEN, 2001). The authority of maps in presenting images of distant places is outstandingly depicted by Matthey Edney's (2003) account of British imperial ambitions in India. While looking to convey broad geographic 
information about the territories of India, the maps published in the late $18^{\text {th }}$ Century by James Rennell also imposed a vision of a British empire on the ruins of the Mughal empire. More accurately, Rennell's maps attained a discursive property in bringing distant places close to home:

His maps of South Asia - both his Hindoostan (1782) and his twice-as-large New Map of Hindoostan (1788) - gave their readers a spatial image with which to refer to "India". They made the place both concrete and real to the participants in the private, parliamentary, and public discussions of the [British East India] company's tangled affairs in South Asia. Rennell's maps were in fact the first to frame the region that we today call India, unlike earlier maps of either the circumscribed limits of the Mughal empire or the whole sweep of the Indies, encompassing Asia from the Indus to China. Rennell's maps constructed India to be the locus of British imperial ambitions for all educated Britons, whether or not they had been to India. (EDNEY, 2003, p. 68)

While this account certainly may not impress most individuals due to its Victorian setting, similar descriptions are present in our day. Maps continue to construct unknown places for the vast majority of the population.

\subsubsection{Language and geographic knowledge}

Another way of acquiring geographic knowledge is through language. In reality, there are countless situations in which there is no choice but to clarify things in words rather than illustrate them graphically (TVERSKY et al., 1994). Language, whether in textual or spoken form, can convey geographic information and also permit individuals to construct integrated mental representations of places and environments that they have never visited. In fact, numerous studies have confirmed that the recognition of spatial arrangements from verbal descriptions is frequently, though not always, as good as that acquired from visual sources (NEWCOMBE; HUTTENLOCHER, 2006; TAYLOR; TVERSKY, 1992a). According to Taylor and Tversky (1992a, p. 495) "language is a surrogate for experience", for just as the purpose of the drawing is to reconstruct an actual picture "so the goal of description was to recreate a picture, in this case, in the mind of another". More significantly, 
the use of language can free individual viewers from their perspective on scenes (TVERSKY, 2000). In other words, an individual can acquire precise geographic knowledge of a specific place or event without ever having to experience it directly.

The natural language used everyday by individuals is composed by sequential arrangements of symbols in which each individual symbol and their sequences contain meaning and a complex, hierarchical structure (PEUQUET, 2002). Each individual symbol that makes up a word is characterized by an assortment of elemental sounds known as phonemes. Each individual symbol is grouped into words, words are grouped into sentences, sentences are grouped into paragraphs, and so on. Accordingly, the different words assume diverse symbolic functions. For example, nouns symbolize things, while adjectives symbolize attributes of things. Verbs, for their part, symbolize actions or events, whereas adverbs signify attributes or modify verbs.

This symbolic diversity, however, contributes to a wide variability in the interpretation in the meaning of words within any given language. As a result, "the variability of symbols denoting different shades of meaning for the same object, event, or attribute, as well as the variability within the rules of proper ordering (i.e., syntax), provides a significant amount of flexibility in natural language for expressing and communicating a wide variety of ideas" (PEUQUET, 2002, p. 162). The possibility of combining words in a variety of different ways also adds to the proliferation of meaning beyond what the individual words allow.

In much the same way as with graphic images, language is significantly broadened by way of imagery and metaphor (PEUQUET, 2002). Due to the fact that images and metaphors are mechanisms of thought, they extend the meaning of language by invoking the imagination. More precisely, as a result of working through an individual's imagination, these mechanisms extend the use of cognitive knowledge by relating dissimilar spheres of knowledge and summoning mental scenes in the "mind's eye".

The resulting diversity in interpretation complicates the capacity for transmitting spatial knowledge through language. Newcombe and Huttenlocher identi- 
fy at least three ways in which language demonstrates difficulty in conveying spatial information:

First, it is difficult to capture metric knowledge without using technical terms. Instead, language naturally groups space into categories, such as "front" and "back". Second, ambiguity can arise in speaking about space because various frames of reference are possible for many spatial terms, so that "front" can mean two different locations depending on the system in use. Third, language is sequential, so that speaking must select a specific order in which to mention the spatial relations in scenes. (NEWCOMBE; HUTTENLOCHER, 2006, p. 760)

Despite these short-fallings, it has been repeatedly demonstrated that language can consistently and successfully convey geographic knowledge (GOLLEDGE; STIMSON, 1997; LANDAU; JACKENDOFF, 1993; TAYLOR; TVERSKY, 1992a; 1992b). According to Barbara Landau (2002), just like the assembly and usage of maps, the individual's ability to represent objects, motions, and their spatial relationships through language is a particularity of the human species which surfaces early in development without formal training. The process that endows individuals with the capacity to learn language from a very tender age is in harmony with two of Piaget's principles regarding early development. The initial principle states that in the first two years of life knowledge is centered on the individual's personal interaction with the environment. In this stage the child establishes the foundations for understanding language and other higher level knowledge structures. The second principle asserts that existing knowledge is revised and conceptually reorganized as individuals develop, discerning the structure of language, along with its general rules and patterns. This principle also recognizes the growing ability of children to think in abstract terms, meaning a better understanding of the "relationships between symbols of language, and between the symbols and the world as perceived" (PEUQUET, 2002, p. 164).

Therefore, children learn the meaning of words through a process of progressive refinement based on sensory perception. Starting from very simple criteria for attributing names to perceived objects, children progressively learn to better distinguish the perceived objects through the use of supplementary sensory crite- 
ria such as sound, color, shape, etc. Children's categorical definition of the various objects will develop over time as they reach adulthood. Throughout this process children will learn how to combine words into phrases and sentences and, in due course, develop conceptual hierarchies that allow for creating and understanding metaphors through abstract thought. Nevertheless, the development of knowledge acquired through language is also the result of a parallel and sequential process of top-down and bottom-up acquisition (DENHIERE; MANDL, 1988). As a result, language conveys meaning that is concurrently associated with the individual's existing knowledge. The ensuing mental representation results from a top-down process guided by schemata and bottom-down process guided by the text features that integrates each to form a mental model.

While we are certainly aware that language is structured around a set of culturally specific system of symbols, scientific evidence has demonstrated the existence of a common structure in spatial expressions amongst different languages. In the study conducted by Munnich, Landau and Dosher (2001, p. 198) empirical findings "suggest that both language and memory draw on the same kinds of spatial properties, including axial structure and contact/support”. While the authors acknowledge that there are similarities and differences in various aspects of spatial language, revealing the complex nature of the relationship, the commonalities identified do give the impression that both perception and linguistic representations resort to a general cognitive structure of spatial knowledge that exists at a more profound level.

The studies conducted in recent years have revealed numerous universal structural mechanisms contained by language for representing and assigning spatial information. However, Peuquet has summarized the principal ways in which language cognitively organizes spatial knowledge:

1. Through schematization, spatial language disregards many geometric details. This parallels cognition in generalizing knowledge, disregarding unneeded information. It also appears that the classificatory system in language parallels that used cognitively as a means of both organizing and minimizing information. [...] 
2. The separation of relative and absolute-metric within the distinction of grammatical (closed class) and lexical elements of language, respectively, parallels the relative and absolute views of space and time seen in cognition and, historically, in various cultures. These are also reflected in the frames of reference used. Spatial relationships expressed within the most basic elements in language, the closedclass elements, are the relative relationships associated with early learning and direct interaction with the world. The use of a figure-ground framework in linguistic expressions of relative spatial relationships also parallels human conceptualization as relationships between objects; relative relationships are viewed as a property of objects that relates them other objects.

3. The mechanisms of focus of attention and shifting attention in language parallels the cognitive process of an observer experiencing a visual scene. This cognitive process involves both sequential process of examination/ exploration of elements in the scene, as described by Neisser, and a hierarchical strategy, as described by Marr. (PEUQUET, 2002, p. 172-173)

On the whole, what these cognitive organizations indicate is that language is a representation of shared mental models of the external world, rather than a direct symbolization of it. These representations can be highly elaborate and complex or leisurely and entertaining. We encounter representations of different places in our every day life. Whether we are listening to the news or simply reading a book, we cannot avoid descriptions of different places and imagine them (consciously or not) in our mind.

The epitomic example of the power of language to convey political knowledge about distant geographic contexts is illustrated in George Kennan's, 8000word, "Long Telegram" to Secretary of State Marshall on the impending Soviet threat. Kennan (1946) catalyzed the bipolar paradigm emerging from the Second World War by depicting two antagonistic regimes that would engage in struggle for control of a divided world. In his telegram, Kennan portrayed the Soviet outlook as one which comprehended an "antagonistic capitalist encirclement" of the USSR. This antagonism would lead, in the words of Stalin, to an inevitable clash between the US and USSR: 
In course of further development of international revolution there will emerge two centers of world significance: a socialist center, drawing to itself the countries which tend toward socialism, and a capitalist center, drawing to itself the countries that incline toward capitalism. Battle between these two centers for command of world economy will decide fate of capitalism and of communism in entire world. (KENNAN, 1946, p. 2)

According to Kennan, this perspective would obviously guide Soviet foreign policy in advancing its interests and objectives while undermining its adversary's policies. Yet, despite the Long Telegram's exquisite illustration of a politically partitioned world, the text also impresses for its ability to represent the social dimension of the Russian people. The outlook put forward above does not, in Kennan's word, represent the natural view of the common Russian population. Rather, the antagonistic view is promulgated by the Communist Party propaganda due to its traditional and instinctive insecurity in relation to foreign influence and penetration, especially Western contact. This insecurity resulted from the geographic threats that accumulated throughout the centuries of Russian history. Indeed, for Kennan, it was geography that organized and secured the political system in Russia:

It was no coincidence that Marxism, which had smouldered ineffectively for half a century in Western Europe, caught hold and blazed for first time in Russia. Only in this land which had never known a friendly neighbor or indeed any tolerant equilibrium of separate powers, either internal or international, could a doctrine thrive which viewed economic conflicts of society as insoluble by peaceful means. After establishment of Bolshevist regime, Marxist dogma, rendered even more truculent and intolerant by Lenin's interpretation, became a perfect vehicle for sense of insecurity with which Bolsheviks, even more than previous Russian rulers, were afflicted. In this dogma, with its basic altruism of purpose, they found justification for their instinctive fear of outside world, for the dictatorship without which they did not know how to rule, for cruelties they did not dare not to inflict, for sacrifices they felt bound to demand. Thus Soviet leaders are driven necessities of their own past and present position to put forward which $\left({ }^{*}\right)^{12}$ outside world as evil, hostile and menacing, but as bearing within itself germs of creeping disease and destined

\footnotetext{
${ }^{12}$ Apparent omission in Kennan's text.
} 
to be wracked with growing internal convulsions until it is given final coup de grace by rising power of socialism and yields to new and better world. (KENNAN, 1946, p. 6)

We can deduce from Kennan's words that Russia was a place of authoritarianism and ruthlessness regardless of Marxist ideology. It was the facts of geography that attributed this callous character to the different regimes all through history. It was also geography that allowed for an ideology of mistrust and oppression to establish itself and thrive. But it would also be geography that would allow the US to prevail over Soviet communism. For Kennan, US strategy should rely on a strategy of spatial containment which would limit the proliferation of Soviet power. The importance of Kennan's text cannot be underestimated. As John Lewis Gaddis (2005, p. 18) insists "rarely in the course of diplomacy is it given to one individual to express, within the compass of a single document, ideas of such force and persuasion that they immediately change the direction of a nation's foreign policy". Although Kennan's recommendations were not followed entirely, his narration of the situation cast the outline for the majority of American's overarching geographic mental maps throughout the Cold War.

This rationale was underscored by Tuan (1991, p. 685) when he acknowledged that although language cannot transform nature per se, it can "direct attention, organize insignificant entities into significant composite wholes, and in doing so, makes things formerly overlooked - and hence invisible and nonexistent - visible and real". In this way, Kennan presented a cohesive and simple image of the threat to US policy-makers and public. This constructional capacity of language is reinforced by written records. By recording geographic narratives in written text they achieve a greater degree of stability and permanence, particularly with the successive publication and dissemination. Kennan's long telegram, although a classified document, was promptly disclosed and the underlying ideas were propagated and disseminated through various channels and sources.

However, the power of language to convey geographic knowledge need not be embodied in such an extensive form as Kennan's telegram. Small and general descriptions, or labels, suffice in assigning geographic information. Once again we evoke Tuan to elucidate: 
Generic terms are not as powerful evocators of place as are proper names. To call a feature in the landscape a "mount" is already to impart a certain character, but to call it "Mount Misery" is to significantly enhance its distinctiveness, making it stand out from other rises less imaginatively called. [...] Naming is power - the creative power to call something into being, to render the invisible visible, to impart a certain character of things. (TUAN, 1991, p. 688)

We have witnessed this phenomenon at work in foreign policy innumerable times throughout history. Most recently, the evocation of an "axis of evil" provided the Bush Administration with a new view of the post-September 11 political world. In other words, the axis of evil metaphor structured the political world in the traditional bipolar arrangement of the Cold War, where adversaries were commingled into a monolithic whole. Furthermore, it shaped the political world in order to simplify the complexity of international politics. More precisely, the axis of evil concept allowed "Americans to think that evil is a feature of particular geographical regions, faraway countries about which they know little, and thus not of Texas or Wyoming, which are part of the Kingdom of Good" (HERADSTVEIT; BONHAM, 2007, p. 426).

However, language is usually combined with graphic images in conveying geographic knowledge. While both can accomplish this desiderate independently, we regularly encounter them together in the most assorted means. Consider how atlases utilize both maps and textual descriptions to inform their readers about the geographic particularities of the country or region they are appraising. Equally suggestive, tourist maps also apply both sources of information in order to help travelers interpret the local environment. The same holds true for maps published by the press.

The interaction of graphic images and language is possible due to the numerous resemblances they possess. Regardless of assuming different forms of external knowledge, graphics and language share a host of analogous properties, specifically (PEUQUET, 2002, p. 180):

1. Both are symbolic systems with a vocabulary and grammar; 
2. Both have a hierarchical composition, with groupings and relationship among the elements;

3. Both equally transmit extrinsic and intrinsic meaning;

4. Neither represents reality directly, constituting rather representations of our cognitive knowledge of the world;

5. Both are selective abstractions of cognitive knowledge;

6 . Both are reflections of cognitive structure.

\section{Concluding remarks}

The study of geographic mental maps has remained a discrete field of research in international politics. While some studies have appeared in recent years, we have witnessed a proliferation of conceptual and methodological approaches to mental maps. This conceptual and methodological diversity is also accompanied by a lack of the necessary theoretical framework to properly understand the influence of mental maps in foreign policy. In other words, while geographic mental maps are applied to try to identify decision-makers geographic constructs, we lack an appropriate account of how these mental maps are formed and how they manipulate our understanding of the political environment.

In this article we have briefly and heuristically presented the principle ways in which individuals acquire information about their geographic environment. Whereas direct and indirect sources comprise the sum of our acquired geographic knowledge, we emphasize the role of secondary learning for understanding the global political environment. In particular, due to the extensive geographic scale involved in foreign policy decision-making, graphic images and language are critical in conveying information. In this sense, foreign policy decision-maker's geographic mental maps are, in large part, the product of geographic knowledge acquired through indirect sources derived from official bureaucratic organizations, personal and technological networks, and other informal channels.

However, regardless of the origin of the geographic information, we must keep in mind that it never represents reality directly. Rather, it constitutes a representation of our cognitive knowledge of the world, which is subject to distortions and misrepresentations. Acknowledging this selective and abstract nature of men- 
tal maps allows for a better understanding of the geographic dimension inherent in foreign policy decision-making.

\section{References}

AGNEW, John. Geopolitics- Re-visioning World Politics. New York: Routledge, 2003.

ALLEN, Gary. Strengthening Weak Links in the Study of the Development of Macrospatial Cognition. In: COHEN, R. (Ed.) The Development of Spatial Cognition. Hillsdale, New Jersey: Lawrence Erlbaum Associates, Publishers, 1985. p. 301-321.

ALLISON, Graham; ZELIKOW, Philip. Essence of Decision: Explaining the Cuban Missile Crisis. New York: Longman, 1999.

BATTERSBY, Sarah; MONTELLO, Daniel. Area Estimation of World Regions and the Projection of the Global-Scale Cognitive Map. Annals of the Association of American Geographers. Washington, DC, v. 99, n. 2, p. 273-291, 2009.

BIALASIEWICZ, Luiza et al. Performing Security: The Imaginative Geographies of Current US Strategy” Political Geography. v. 26, n. 4, p. 405-422, 2007

BILGIN, Pinar. Whose 'Middle East'? Geopolitical Inventions and Practices of Security. International Relations. Aberystwyth, v. 18, n. 1, p. 25-41, 2004.

BLOODGOOD, Elizabeth. What do Decision-makers Know? The Sources and Evaluation of Information in Foreign Policy-making. Paper delivered at the Annual Meeting of the American Political Science Association. 2003. Available at: < http:// www.allacademic.com/meta/p64568_index.html>. Access at: nov. 2009.

CASEY, Steven; WRIGHT, Jonathan (Eds.). Mental Maps in the Era of Two World Wars. New York: Palgrave-Macmillan, 2008.

CLAVAL, Paul. História da Geografia. Lisboa: Edições 70 Lda, 2006.

COHEN, Robert. What's So Special About Spatial Cognition. In: COHEN, R. (Ed.) The Development of Spatial Cognition. Hillside, New Jersey: Lawrence Erlbaum Associates, p. 1-12, 1985. 
COTTAM. Martha et al. Introduction to Political Psychology. Mahwah, New Jersey: Lawrence Erlbaum Associates, 2004.

CRIEKEMANS, David. Where 'geopolitics' and 'foreign policy analysis' once met: the work of Harold and Margaret Sprout and its continued relevance today. Paper presented at the annual meeting of the ISA's 50th Annual Convention "Exploring the Past, Anticipating the Future". Available at: <http://www.allacademic.com/one/isa/ isa09/index. php? cmd= isa09_search\&offset=0\&limit=5\&multi_search_search_ mode=publication \&multi_search_publication_fulltext_mod=fulltext\&textfield_ submit=true\&search_module=multi_search\&search=Search\&search_field=title_ idx\&fulltext_search $=$ Where + Geopolitics+and+Foreign + Policy+Analysis + Once + Met $\% 3 \mathrm{~A}+$ The + Work + of + Harold + and + Margaret + Sprout + and $+\mathrm{its}+$ Continued $+\mathrm{R}$ elevance+Today>. Access at: Jun. 2009.

DENHIERE, Guy; MANDL, Heinz. Knowledge Acquisition from Text: Introduction. European Journal of Psychology of Education. Lisboa, v. 3, n. 2, p. 107-110, 1988.

DIJKINK, Gertjan. Geopolitical Codes and Popular Representations. GeoJournal. Netherlands, v. 46, n. 4, p. 293-299, 1998

DODDS, Klaus-John. Geopolitics and Foreign Policy: Recent Developments in Anglo-American Political Geography and International Relations. Progress in Human Geography. Manchester, v.18, n. 2, p. 186-208, 1994.

DOWNS, ROGER; STEA, David. Cognitive Maps and Spatial Behavior: Process and Products. In: Downs, R; Stea, D. (Eds.) Image and Environment: Cognitive Mapping and Spatial Behavior. New Brunswick, New Jersey: Transaction Publishers, 2005. p. 8-26.

EDNEY, Matthew. Bringing India to Hand: Mapping an Empire, Denying Space. In: NUSSBAUM, F. (Ed.) The Global Eighteenth Century. Baltimore, Maryland: The Johns Hopkins University Press, 2003. p. 65-78.

FREUNDSCHUH, Scott; EGENHOFER, Max. Human Conceptions of Spaces: Implications for Geographic Information Systems" Transaction in Geographic Information Systems. v. 2, n. 4, p. 361-375, 1997. Available at:< http://reference. $\mathrm{kfupm} . e d u . s a / c o n t e n t / h / \mathrm{u} / \mathrm{human}$ conceptions_of_spaces_implication_735735. pdf $>$. Access at: May 2009.

GADDIS, John Lewis. Strategies of Containment: A Critical Appraisal of American National Security Policy during the Cold War. New York: Oxford University Press, 2005. 
GEORGE, Alexander. Presidential Decisionmaking in Foreign Policy: The Effective Use of Information and Advice. Boulder, Colorado: Westview Press, 1980.

GLASSMAN, Jim. "On the Borders of Southeast Asia: Cold War geography and the construction of the other". Political Geography. Burlington, MA, v. 24, p. 784-807, 2005.

GOLLEDGE, Reginald. The Nature of Geographic Knowledge. Annals of the Association of American Geographers. Washington, DC, v. 92, n. 1, p.1-14, 2002.

GOLLEDGE, Reginald. Environmental Cognition. In: Stokols, D; Altman, I. (Eds.). Handbook of Environmental Psychology. New York: John Wiley \& Sons, 1987. p. 131-174.

GOLlEDGE, Reginald; STIMSON, Robert. Spatial Behavior: A Geographic Perspective. New York: The Guilford Press, 1997.

GORDON, Ian. Theories of Visual Perception. New York: Psychology Press, 2004.

HART, Roger; MOORE, Gary. The Development of Spatial Cognition: A Review. In: Down, R; Stea, D. (Eds.) Image and Environment: Cognitive Mapping and Spatial Behavior. London: Arnold Publishers, 1974. p. 246-288.

HENRIKSON, Alan. FDR and the 'World-Wide Arena. In: WOOLNER, D; KIMBALL, W; REYNOLDS, D (Eds.) FDR's World: War, Peace, and Legacies. New York: Palgrave-Macmillan, 2008. p. 35-61.

HENRIKSON, Alan. Distance and Foreign Policy: A Political Geography Approach. International Political Science Review. Montreal, v. 23, n. 4, p. 437-466. 2002.

HENRIKSON, Alan. The Geographical 'Mental Maps' of American Foreign Policy Makers. International Political Science Review. Montreal, v. 1, n. 4, p. 495-530, 1980a

HENRIKSON, Alan. America's Changing Place in The World: From 'Periphery' to 'Centre'?. In: Gottman, J. (Ed.) Centre and Periphery: Spatial Variation in Politics. Beverly Hills, California: Sage Publications, 1980b. p.73-100.

HENRIKSON, Alan. The Map as an 'Idea': The Role of Cartographic Imagery during the Second World War. The American Cartographer. Falls Church, VA, v. 2, n. 1, p. 19-53, 1975. 
HERADSTVEIT, Daniel; BONHAM, G. Matthew. What the Axis of Evil Metaphor Did to Iran. Middle East Journal. Washington, DC, v. 61, n. 3, p. 421-440, 2007.

HOLSTI, Ole. The Belief System and National Images: A Case Study In: Holsti, O. (Ed.) Making American Foreign Policy. New York: Routledge, 2006a. p. 23-32.

HOLSTI, Ole. Cognitive Process Approaches to Decision-Making: Foreign Policy Actors Viewed Psychologically. In: Holsti, O. (Ed.) Making American Foreign Policy. New York: Routledge, 2006b. p. 33-51.

HOLSTI, Ole. Foreign Policy Formation Viewed Cognitively. In: AXELROD, R. (Ed.) Structure of Decision: The Cognitive Maps of Political Elites. Princeton, New Jersey: Princeton University Press, 1976. p. 18-54.

HUDSON, Valerie; VORE, Christopher. Foreign Policy Analysis Yesterday, Today, and Tomorrow. Mershon International Studies Review. v. 39, n. 2, p. 209-238, 1995.

KANT, Immanuel. Critique of Pure Reason. New York: The Colonial Press, 1900.

KENNAN, George. Telegram from George Kennan to George Marshall ["Long Telegram"]. Harry S. Truman Library and Museum. 1946. Available at:<http:// www.trumanlibrary.org/whistlestop/study_collections/coldwar/ documents/ index.php? documentdate=1946-02-22\&documentid=6-6\&studycollectionid=\&p agenumber $=1>$.September 2010 .

KIESLER, Sara; SPROULL, Lee. Managerial Response to Changing Environments: Perspectives on Problem Sensing from Social Cognition Administrative Science Quarterly. Ithaca, NY, v. 27, n. 4, p. 548-570, 1982.

KULHAVY, Raymond; STOCK, William. How Cognitive Maps are Learned and Remembered. Annals of the Association of American Geographers. Washington, DC, v. 86, n. 1, p. 123-145, 1996.

LANDAU, Barbara. Spatial Cognition in Ramachandran, V. (Ed.) Encyclopedia of the Human Brain, Volume IV. San Diego, California: Academic Press, 2002. p.395418.

LANDAU, Barbara; JACKENDOFF, Ray. What and Where in Spatial Language and Spatial Cognition. Behavioral and Brain Sciences. New York, v. 16, p. 217-238, 1993. 
LATHAM, Andrew. China in the Contemporary American Geopolitical Imagination. Asian Affairs: An American Review. Washington, DC, v. 28, n. 3, p. 138-145, 2001.

LE RIDER, Jacques. Mitteleuropa, Zentraleuropa, Mittelosteuropa: A Mental Map of Central Europe. European Journal of Social Theory. Cambridge, v. 11, n. 2, p. 155-169, 2008.

LEWIS, Martin; WIGEN, Kären. The Myth of Continents: A Critique of Metageography. London: University of California Press, 1997.

LLOYD, Robert. Understanding and Learning Maps. In: KITCHIN, R; FREUNDSCHUH, S. (Eds.) Cognitive Mapping: Past, Present and Future. London: Routledge, 2002. p. 84-107.

LLOYD, Robert. Cognitive Maps: Encoding and Decoding Information. Annals of the Association of American Geographers. Washington, DC , v. 79, n. 1, p. 101-124, 1989.

LLOYD, Robert. A Look at Images. Annals of the Association of American Geographers. Washington, DC, v. 72, n. 4, p. 532-548, 1982.

LYNCH, Kevin. The Image of the City. Cambridge, Massachusetts: The MIT Press, 1960.

MARK, David; et al. Cognitive Models of Geographical Space. International Journal of Geographical Information Science. London, v. 13 , n. 8, p. 747-774, 1999.

MINTZ, Alex; DEROUEN Jr., Karl. Understanding Foreign Policy Decision Making. New York: Cambridge University Press, 2010.

MONMONIER, Mark. How to Lie with Maps. Chicago: The University of Chicago Press, 1999.

MONTELLO, Daniel. A New Framework for Understanding the Acquisition of Spatial Knowledge in Large-Scale Environments. In: EGENHOFER, M; GOLLEDGE, R (Eds.) Spatial and Temporal Reasoning in Geographic Information Systems. New York: Oxford University Press, 1998. p. 143-154.

MOORE, Gary; GOLLEDGE, Reginald. Environmental Knowing: Theories and Concepts. In: MOORE, G; GOLLEDGE, R. (Eds.) Environmental Knowing: Theories, Research and Methods. Stroudsburg, Pennsylvania: Dowden, Hutchinson \& Ross, 1976. p. 3-24. 
MUNNICH, Edward; LANDAU, Barbara; DOSHER, Barbara. Spatial Language and Spatial Representation: A Cross-Linguistic Comparison Cognition. Amsterdam, v. 81, n. 3, p. 171-207, 2001.

NEWCOMBE, Nora; HUTTENLOCHER, Janellen. Development of Spatial Cognition. In: KUHN, D; SIEGLER, R. (Eds.) Handbook of Child Psychology, Volume II. Hoboken, New Jersey: John Wiley \& Sons, 2006. p. 734-776.

O'LOUGHLIN, John; GRANT, Richard. The Political Geography of Presidential Speeches, 1946-87. Annals of the Association of American Geographers. Washington, DC, v. 80 , n. 4 , p. 504-530, 1990.

Ó TUATHAIL, Gearóid. The Bush Administration and the 'End' of the Cold War: A Critical Geopolitics of US Foreign Policy in 1989 Geoforum. Oxford, v. 23, n. 4, p. 437-452, 1992.

Ó TUATHAIL, Gearóid; AGNEW, John. Geopolitics and Discourse: Practical Geopolitical Reasoning in American Foreign Policy. In: Ó TUATHAIL, G; DALBY, S; ROUTLEDGE, P. (Eds.) The Geopolitics Reader. New York: Routledge, 1998. p. 78-91.

PEUQUET, Donna. Representations of Space and Time. New York: The Guildford Press, 2002.

PIAGET, Jean. Development and Learning. In: GAUVAIN, M; COLE, M; (Eds.) Readings on the Development of Children. New York: W. H. Freeman and Company, 1997. p. 19-28.

PLACK, Christopher. Auditory Perception In: LAMVERTS, K; GOLDSTONE, R. (Eds.) Handbook of Cognition. London: Sage Publications, 2005. p. 71-104.

RENSHON, Jonathan. Why Leaders Choose War: The Psychology of Prevention. Westport, Connecticut: Praeger Security International, 2006.

ROSATI, Jerel. A Cognitive Approach to the Study of Foreign Policy. In: NEACK, L; HEY, J; HANEY, P (Eds.) Foreign Policy Analysis: Continuity and Change in its Second Generation. Englewood Cliffs, New Jersey: Prentice Hall, 2005. p. 49-70.

SCHEFFLER, Thomas. Fertile Crescent', 'Orient', 'Middle East': The Changing Mental Maps of Southwest Asia. European Review of History. Oxfordshire, v. 10, n. 2, p. 253-272, 2003. 
SCHULTEN, Susan. The Geographical Imagination in America, 1880-1950. Chicago: The University of Chicago Press, 2001.

SHETTLEWORTH, Sara. Cognition, Evolution, and Behavior. New York: Oxford University Press, 2010.

SLOAN, Geoffrey. Geopolitics in the United States Strategic Policy, 1890-1987. New York: St. Martin's Press, 1988.

SPROUT, Harold; SPROUT, Margaret. Geography and International Politics in an Era of Revolutionary Change. Journal of Conflict Resolution. Michigan, v. 4, n. 1, p. 145-161, 1960.

TAYLOR, Holly; TVERSKY, Barbara. Descriptions and Depictions of Environments. Memory \& Cognition. Austin, Texas, v. 20, n. 5, p. 483-496, 1992a.

TAYLOR, Holly; TVERSKY, Barbara. Spatial Mental Models Derived from Survey and Route Descriptions. Journal of Memory and Language. New York, v. 31, p. 261 292, 1992 b.

TETLOCK, Philip; MCGUIRE JR., Charles. Cognitive Perspectives on Foreign Policy. In: IKENBERRY, G. J. (Ed.) American Foreign Policy: Theoretical Essays. Massachusetts: Addison Wesley Longman, 1999. p. 504-521.

TUAN, Yi-Fu. Language and the Making of Place: A Narrative-Descriptive Approach. Annals of the Association of American Geographers. Washington, DC, v. 81, n. 4, p. 684-696. 1991.

TUAN, Yi-Fu. Images and Mental Maps. Annals of the Association of American Geographers. Washington, DC, v. 65, n. 2, p. 205-213. 1975.

TVERSKY, Barbara. Structures of Mental Spaces: How People Think About Space” Environment and Behavior. California, v. 35, n. 1, p. 66-80. 2003.

TVERSKY, Barbara. Remembering Spaces in Tulving, E; Craick, F. (Eds.) Handbook of Memory. New York: Oxford University Press, 2000. p. 363-378.

TVERSKY, Barbara. Cognitive maps, cognitive collages, and spatial mental models in Frank, A; Campari, I; (Eds.): Spatial Information Theory: A Theoretical Basis for GIS. Berlin: Springer-Verlag, 1993. p. 14-24. 
TVERSKY, Barbara; FRANKLIN, Nancy; TAYLOR, Holly; BRYANT, David. Spatial Mental Models from Descriptions. Journal of the American Society for Information Science. Maryland, v. 45, n. 9, p. 656-668, 1994.

VERTZBERGER, Yaacov. The World in their Minds: Information Processing, Cognition and Perception in Foreign Policy Decisionmaking. Stanford, California: Stanford University Press, 2002.

VOSS, James. On the Representation of Problems: An Information-Processing Approach to Foreign Policy Decision Making. In: SYLVAN, D; VOSS, J. (Eds.) Problem Representation in Foreign Policy Decision Making. Cambridge: Cambridge University Press, 1998. p. 8-26.

WALKER, Martin. Variable Geography: America's Mental Maps of Greater Europe. International Affairs. London, v.76, n. 3, p. 459-474, 2000. 